\title{
DK
}

771

K7G7

1902

KELL 


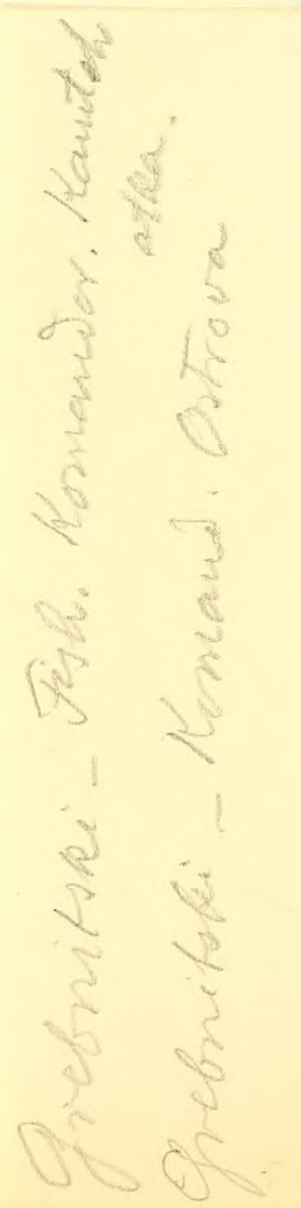




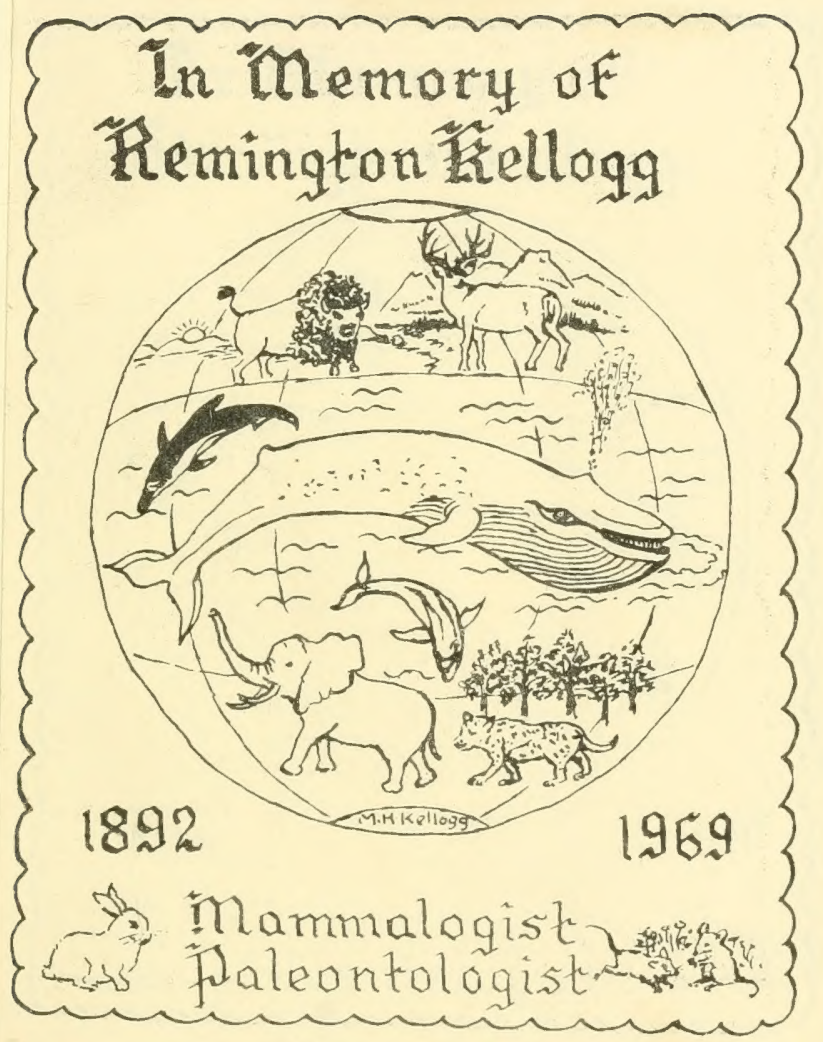




The Ministry of the Agriculture and Domain. Department of Agriculture.

\section{COMMANDER ISLANDS}

by N. A. Grebnitzky.

Translated by Louise Woehlcke.

St. Petersburg. Printed by W. Kirshbaum. 


\section{TABLE OF CONTENTS.}

Pages.

I. The Geology of the Commander Islands . . . 3

II. The Animal life . . . . . . . . . . . . 7

III. Population of the Commander Islands . . . . 40

List of photographs. . . . . . . . . . . 44 


\section{The Geology of the Commander Islands.}

The Commander Islands (Behring, Copper and 2 small islands) belong to the type of continental Islands (they are only partly vulcanic). They are separeted from the Peninsula Kamtchatka by a strait of about go geograph. miles. From the Aleutian Islands they are separated by a depth of more than 1600 fathoms. They are situated on the boundary of vulcanic activity of the two vulcanic groups: the Japanese-Kurile, Kamtchatka and Aleutian Islands. They owe their appearance to vulcanic activity, which left deep traces. The geological age of the Islands is a very young one. Sedimentary rocks are known as follows: the tertiary-pliocene, but the more important sediments are the post-pliocene and alluvial ones, which are of very recent origin. Fossils are very insignificant in consequence of the vulcanic activity-metamorphosing the sedimentary layers into schistic layers. By the character of the fossils one may conclude, that the layers are formed through shallow water. Predominating are slates metamorphosed in various ways, sand stones, conglomerates of an immense power. Feldspath basalt form vulcanic rocks, which have broken the previous layers and destroyed their horizontality. The strangest vulcanic activity was on Copper Isl. Basaltic eruptions occurred more than once, which may be concluded by its structure. The earliest eruptions were considerably destroyed by the influence of atmosphere and water. Dislocations were more energetically proved on Copper Isl., where one comes across a suite of layers in an almost vertical position. The chain of mountains on the Islands extend from Nord-West to SouthEast. On Behring Island this chain is crossed by narrow 
valleys, through which run rapid streams occasionally in cascades, falling into the sea. All the summits, owing to atmospheric influence, which rapidly destroys the schistic rocks, take the shape of cones. The schistic rock on Behring Island broadens in the direction from South-East to Nord-West, changing in the northern part into a plateau, which extends from East to West and is intercepted by deep valleys, in which the largest lake of the Islands-Sarannoye is situated. Near it, standing separately, are the Table(Stolovoi) hills, enclosing the swamp below to its present state. The plateau is divided into three terraces, sloping towards the sea except in the N. Eastern part, where it breaks off steep into the sea, forming a long submerged reef. The eastern part of the mountain chain has a broad sea-shore; steep descents, except the extreme southern part. The shore is shoaly with reefs, extending far out into the sea. There are proofs existing, that the beach was higher, as molluscs Pholas were found there; one may state, that also at present the shore rises as the part on which Behring's vessel was stranded, lies on a entirely dry place far off from the boundaries of the strait and those reefs, over which the vessel lurched, are connected with the shore. A steep shore, which has a precipitous incline under the water exists on the S. Eastern part of Behring Island, but the principal parts of the steep rocky shores have an increase by alluvium-which is formed by the waves depositing refuse of rocks and sand. This alluvial reef and the shores, which recede into the land are the means of lowering the sea level. A similar shore is often bounded on one side by a flat beach with shallow water. The shore, for instance which is the principal settlement on the Behring Island, is of this character and the same kind of shore is again found on the eastern part of this Island. On the Eastern boundary of Copper Island, steep alluvial shores predominate. The type of this beach must be placed with the type of longitudinal shore (Richthoffen's Classification), characterised by their 
monotonous form extending parallel with the mountain chain.

In the North of Behring Isl. along the western shore there are sand-hills. The largest sand-hills in breadth and height are those near the Nicolsky village, as they are almost perpendicular with the mountain chain; they extend as far as the N. W. cape, interrupted in this extension by two basaltic eruptions. The sand-hills situated towards the South of the colony are parallel with the mountain chain and lie direct upon it. The distribution and growth of the sand-hills still continues at the present time; they fill the swamp, raising its level and moving into the sea, increase the space of shallow shore, always moving the port of the village. On Copper Isl. there are only two places known, where there are sand-hills; there they connect with the mountain chain, the S. Eastern part of the Copper-Island, which was formerly a separate island,and a small mountain-chain, lying separately, is connected with the range. The nature of the shore, the alluvial sand was the means of giving its name to some places called Sand-bays (there are several on the island).

Insignicant sand-hills are to be found near the Korabelnowskoïe village, where they filled up a bay, that had been there before. The sand-hills are of great economic value to the local population owing to the fact, that the snow on the tops of the sand-hills does not stay there long and cannot attain any depth, these hills serve as a splendid pasture-land for cattle in winter. But in consequence of continual pasture, the sant-hills have no opportunity of being densely covered, nor of gaining strength by the growing grass. (The principal plants strenghtening the sand-hills are different kinds of hedgehog-grass). In places where there is no pasture of cattle, the sand-hills are covered with various, but low vegetation. The most instructive denudations are to be found on Behring Isl. Fossils, somewhat well preserved, are to be observed when mounting the Stoloroi hills and in the valley of 
the Kamennaja river. The sea-cow, which disappeared in historical times, but comparatively not very long ago, was found (in most cases) along the Eastern shore of Behring Isl. at a distance from the present boundary of the strait's level. The position of their skeletons lying parallel with the shore prove, that they were deposited there by the waves, which came as far as the foot of the sloping hills and were then buried by heaps of sand and pebblestones, washed in by the sea. The receding sea left behind it a rising wall consisting of pebblestones and sand; two such walls exist along the Eastern shore of Behring Isl, one in immediate vicinity to the foot of the mountain-chain. The strip of shore being so narrow did not afford a possibility of forming lake-basins, which were bordered from the sea by a wall, errected by the same. The place, where Behring's expedition was shipwrecked and on which out of the wreck of the ressel, a new one was built-is at present occupied by sand-hills, which are just forming. In these, remains of the expedition, are to be found in the shape of beads, jet, broken pots, metal parts of fire-arms and amunition etc.

Several times a year the Commander Islands are subject to earth quakes of various natures, but generally slight. Most frequently they occur in February and July and are chiefly felt then. It was observed, that the sererest (wave-like) shocks were felt in the direction from S. W.-N. E. (the general direction of the coast of the Kamtchatka peninsula). The reason of the occurence of these earth quakes in vulcanic or tectonic forms, which is an open question - as there are no scientifically frounded obstrations made. Though it is more correct to say, that the earth-quakes are in connection with the vulcanic activity of the northern group of the Kamtchathit rulcanoes. As collateral result of tarth-quakes one may observe a large drift of sea-forms on to the shore, which live in a great deptl and which are otherwise rarely washed in by the sea. 


\section{Animal life on the Commander Islands.}

The principal riches of the Commander Islands are contained in the Behring Sea, which surrounds them and is closed up by them in the S. W. The depth of hundred fathoms extends in the $\mathrm{N}$. Western direction to the Kamtchatka peninsula, but cannot as yet be precisely stated. But all the roo fathoms depth of the mainland protrude far into the Behring sea. The riches of searegetation are known, and awake in all naturalists great astonishment and admiration, but only Japan can make use of the Asiatic part of the riches, in the Pacific, where they extract out of sea-weeds a valuable glue and prepare ashes, which are used in chemical factories. On the Commander Islands the shore is covered far about ten versts with washed up sea-weeds, which decay on the beach and give the shore a characteristic smell. Such weeds decayed and lixiviated, alcalizided from the sea-salt serve as manure to the small kitchen-gardens, where only potatoes and turnips grow. The sea-weed Melobesia, is piled up in some places in layers of $6-7$ feet high. The most farourable places are flat rocks near the shore and in hollows, cavities in the rocks, here it developes abundantly and lives along with the sea urchin (Echinus neglectus) and is also the favourite food of the seatotter and of many species of Hexagrammus. The sea-weed growths of the littoral zone serve as a dwelling places and a refuge to fishes of the Liparidae, Cottidae, Chiridae and other species and are even 
not disliked by the sea-otter and herds of hair seal. The sea-coast to the depth of 30 fathoms is fairly instructive in its natural richness in crabs, molluses and fish, collections of which are still being made. All that is known up to now, allows the Behring sea to be reckoned as a special zoological sub-region. The Commander Islands are situated exactly on the borders of the two parts of the Behring sea and the N. IV. part of the Pacific. The open sea becomes characteristic through the great quantity of swimming molluses, which serve as food for whales and fur-seals (Gonatus amoenus-squid English authors). Cephalopodes-two species of Octopus are numerous and serve as food to sea-lions and to the population; their young ones are greedily eaten by large fishes (cod, hallibut). Those of the Onychotheutis species (there are two, kinds) grow to marvellous size.

Whales are inhabitants of the open sea and appear in herds from October month and leave the Islands during April, going north towards the pack ice-regions. There are no whales near the Commander Islands from which whale-bones are got; but sometimes the currents bring in single, dead specimens Balaena japonica, as well as Physeter macrocephalus, comparatively more of the latter. During the last few years in consequence of the decrease in whale-killing in general and their departure more towards the north, dead whales are seldom washed on shore. The most numerous and common kind of whale is the Rachionectus glaucus called by the population by mistake the small Coulema. The Hump-back whales (Balaenoptera Velifera, Megaptera) are not as yet determined. The natives of the Commander Islands use the flesh and fat of the whale as food for dogs, and likewise for themselves.

Near the Islands there are two other kinds of whales to be found of the group Ziphiidae, which only became known in a fossilised state in the first part of last century. To this category of whales may be added the Mesoplo- 


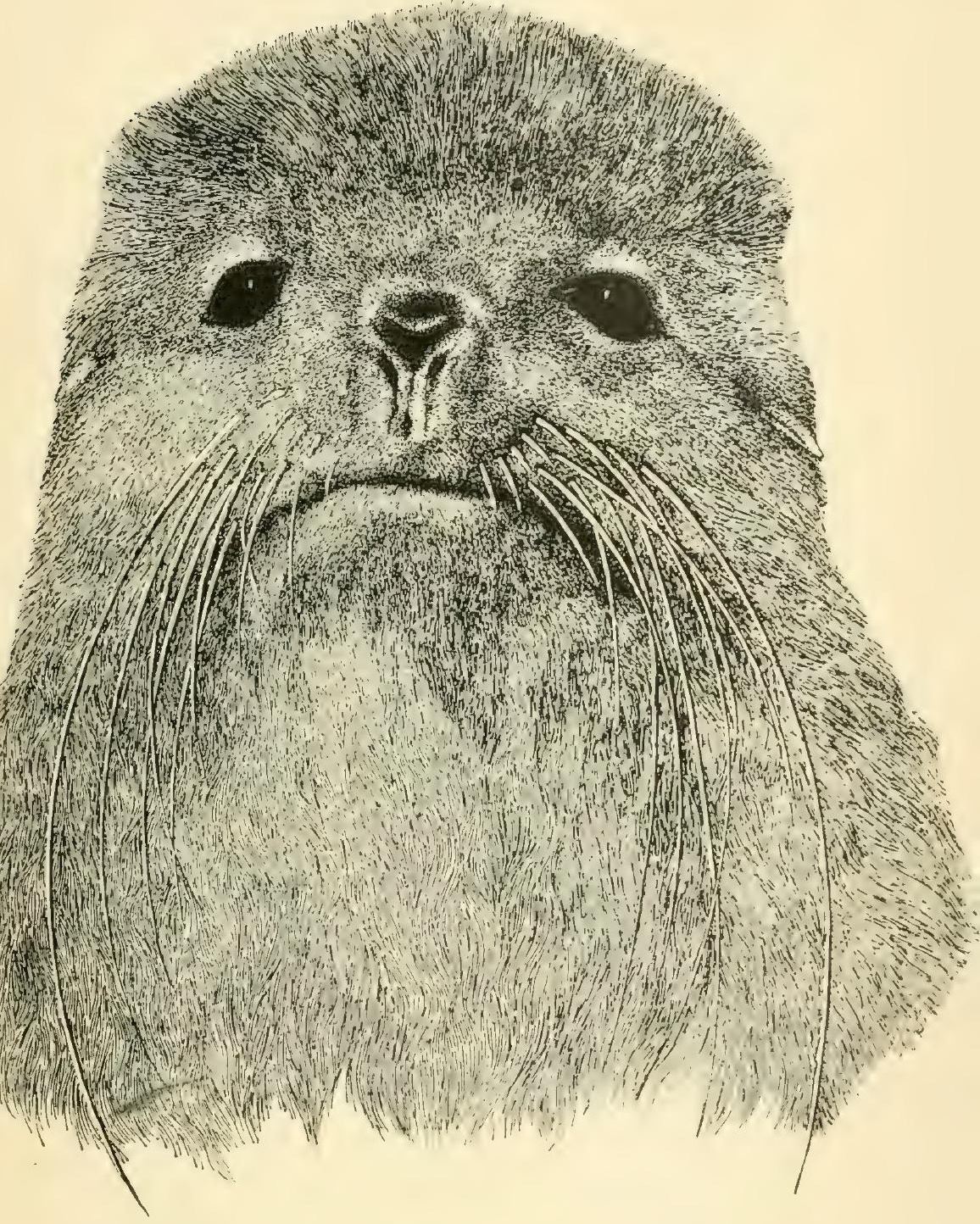

Head of a typical vookery bull.

Drown from nature by Bristow Adams. 


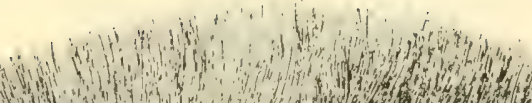

w1

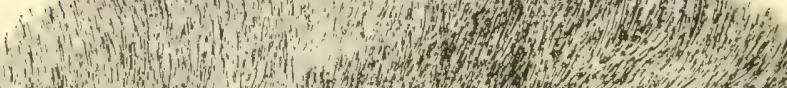

1

i)

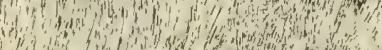

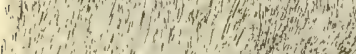

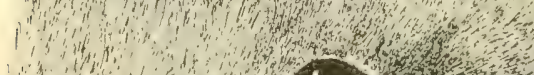

Fin

and

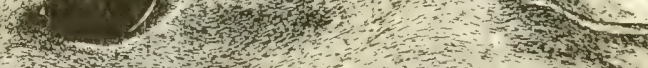

1

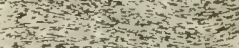

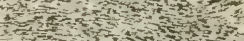

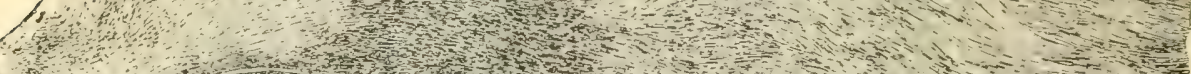

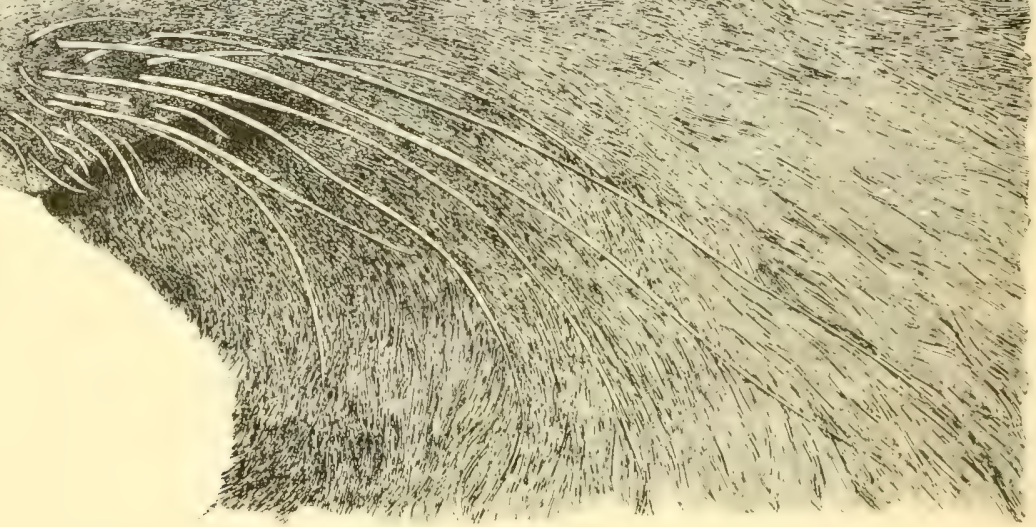

The same head of bull,

in profile. 
don Steinegeri. The flesh and fat of which can only be given to dogs, the natives cannot make use of it for themselves, as the fat has a purging effect; these whales are generally called plavouni.

In spring and summer shoals of the Delphinapterus and Delphinus (2 spec.) visit the Islands, in hunting after fish, during the tide they often jump onto the shore and remain there. Periodically near the shores of the Commander Islands the "Kasatka" (Orca) appears in large shoals. This rapacious whale proves itself to be a veritable plague to the fur seals herd, which it tears into pieces; salmon are driven away by it far from the shore, if the persecution takes place at a distance from the mouth of the river. Competent persons, who have studied the Kasatka-whale in the Japanese sea and on the shores of the yesso Island state, that they are convinced, that these whales are as much to blame in the exterminations of fur seals, as the hunters, who kill the seals in the open sea. Certainly this is exaggeration, but who could, as myself, observe the extermination of seals in lots in the water by Kasatkas, that person will have been convinced, that not only one thousand of fur seals are sacrifices to the wild inclinations of Kasatkas, so well called "killer" by the English. The seals get into a panic fright, as soon as they see the killer's back swimmers, and instead of staying on the shore, they rapidly throw themselves into the water (distort instinct), where they become the sacrifice of the hunting whale, gifted with teeth, capable to tear their-prey. There are some killers every year near the Commander. Isl. but in large shoals they only come periodically. In 1899 there were remarked shoals of $150-200$ individuals. Besides seals the Kasatka extirpates sea-lions, as well as whales, but seldom the latter. Hunting after a sea-lion a killer was thrown out alive onto the shore of Behring Island, an apparition observed too on the American shore, where killers are seldomer still and there in some places (the 
Prybillof Islands) they appear as a rare guest. The Katsatka near the Islands belongs to the zoological species of Orca gladiator, rarely one can see the other kindthe $O$. rectipinna.

The walrus appears as an occasional visitor on the Commander Islands in winter, as well as in summer, coming from the northern shore of Kamtchatka. These last years, in consequence of American hunting-schooners the Karaginsky, as well as the cape of Stolbowoi, where the walrus is nearly entirely exterminated, their the appearance of a walrus is very seldom. The Odobanus obesus in the Eastern Ocean has a more southern geographical boundary, goes as far as the $52^{\prime \prime} \mathrm{n}$. 1., but the breeding herds go only up to the $56^{0} \mathrm{n}$. 1., that is as far as the south border of swimming pack-ice.

Though the American naturalists deal out separatly the walrus of the Eastern Ocean, as an independent species, the Imperial Academie of Sciences in S.-Ptbrg., proved after examining the material, that this was not an scientific foundation, there are even no dates to consider it, as a subspecies. Along the shore of the Behring sea and Ice-Ocean walruses get actively extirpated by the natives, as well as by visiting trading-foreigners.

Already in I88I the American naturalist Edward W. Nelson said: To-day it is safe to say, that the number of these animals in existence, is not over 50 per cent of the number living ten years ago; a heary animal decrease is still going on; this refers to the American, as well as to the Asiatic shore of the Behring-sea and the Arctic Ocean. Whale-hunters wintering on the Barrow cape decreased the capture of walrus to such an "xtent, that the Government had to help the famishing esfuimatux, who through the extinction of walrus lost their principal animal, with which they traded. The statistics of the imported walrus bones by the American trading flext show a yearly decrease, a fact, that also affects the Asiatic (Russian) shore, where the natives 
have fire-arms, the use of which produces a rapid exter mination of walrus.

Hunting walrus with a harpoon becomes a rarity and soon the harpoon will only be mentioned by tradition. The thick skin, as well as the dense cellular-tissue, which is under the skin of the walrus is used. The flesh and fat are used for food, not one part of its inside is lost: the stomach, bowels, the bladder are used in the household, as well as the long bones.

The numerous kind of hair-seal (Phoca) have only one specimen on Copper Island, which forms a small rookery along the $\mathrm{N}$. W. shore close to the sea-otters rookery. The disappearance of the numerous rookeries on Behring Island almost proves, that the geographical conditions have changed rather, than that they have been exterminated by man, because the rookeries disappeared along the whole length of the Island. The rookeries on Copper Island are accidentally preserved, being situated near the rookery of sea-otters, that is in places, that are guarded by special defence. Every year there are captured from Ioo-20o hair seals on Copper Island. The skins of large sized males are used for natives-canoes, the remainder for local boots. The fat is prepared to be kept for future use. Small skins of the hair seal are used for lining snow-shoes.

The Phoca fasciata Zimmerman must be classed among those, that rarely visit the Islands.

The Phoca largha appear more towards spring in small quantities.

The Phoca grönlandica rather frequent.

Eumetopias Stelleri-the sea-lion has for half a century left off being a constant inhabitant of the Commander Islands, where in former times it used to breed. At present, during summer time they appear singly, laying amidst groups of fur seals and the females are sometime's forced by them (then a generation is attained, which for the sake of trade is exterminated, though from scientific: 
point of view this can scarcely be approved of). Small groups of sea-lions make their appearance as constant visitors from autumn until spring, coming from the Kamtchatka peninsula, where the bays are covered with ice and the sheets of ice freezing together on the shore attain considerable sizes. The sea-lion's skin is greatly valued by natives, as out of it are made splendid straps, the skin is used for canoes and seal-canoes and soles for native boots. The bowels are used for making camletswaterproof clothing (2 camlets out of one set of bowels).

The sea-lion as well as the fur seal, belong to the number of migrating animals, but its migration takes place in narrow boundaries. In comparison with the fur seal, the sea-lion is a better swimmer and can stay longer under water, diving rather deep for its prey. Its favourite food is Octopoda. As the sea-lion is, so is the fur seal, more numerous along the American shore, but there too a great decrease is noticed. At the beginning of the XIX century the whole shore of St. George's Island, was occupied by groups of sea-lions. The Russ-Amer. Co. ordered them to be exterminated--their place was taken up by fur seals. In 1873 there were about 25,000 sea-lions on St. Paul's and 9,000 on St. George's Island. The natives drove them away by hundreds; at the beginning of the XX century sea-lion skins had to be brought from other places to supply the wants of the inhabitants, On the Aleutian Islands, where sealions used to be plentiful, the number of sea-lions is now considerably smaller. On the Kamtchatka shore, which is not inhabited at all, along the eastern coast, judging by huntes tales, the number of sea-lion herds has also diminished. One cannot reckon that the extermination by men is the sole reason of their decrease. This animal is not persecuted by white men, and the natives are not able to extirpate it with their primitive way of hunting and their way of moving. 
The fur seal Callorhinus ursinus, together with the seaotter are specimens of the riches of the Commander Islands.

At the beginning of the eightieth years of the last century, taking as a basis of several observations, which existed as the time about the migration of seals, I stated my opinion, that the herds of the Asiatic and the American shores live quite separately and never mix with one another, a statement, which is in exact opposition to the opinion of the American naturalists, who are afraid, that the fur seals of the Prybiloff Islands would leave for the Commander Islands. At the present time, when the migration of the fur seal is well studied; thanks to the development of sea-hunting, also stating, that the Ocean current has an influence of direction of their migration and the distribution of animal organism, which serve as food for fur seals, American naturalists have marked the frontier of distribution between the fur seals of the American and those of the Asiatic shore, though in reality, they are not mixed with each other and they have appointed a special name for the fur seal of the American shore, calling it Callorhinus alascanus, leaving the old name of Callorhinus ursinus to the Asiatic fur seals.

The special arrangements for the American fur seal, as well as the fur seals from the Okhotsk sea (Callorhinus Curilensis) will not bear scientific criticism.

The fur seal of the Commander Islands is superior to the American one in size and all other respects, but it has a coarser fur and is cheaper in market value. Formerly the prices were lower, but the perfection in preparing these skins increased their price. The value and quality of the skins from Robben Island (Call. Curilensis) are greater, than those from the Commander Islands and America, but to great regret of the traders, there are very few of them. $U_{p}$ ) to the present time the designation of the quality of skins, according to the dwelling-place of the seals is not stated, though it is a doubtless fact, that such is the case. 
The fur seal comes on to the Commander Islands for the purpose of breeding, and feeding their young, until they become capable of swimming long distances. Fur seal is the typical sea-animal (of the open sea), the best swimmer, unhesitatingly swims 60 to a Ioo miles searching their favourable food (Gonatus amoenus); should it not be kept on shore by its family duties, which cease, for the male after having fecundated all the females of his harem; the female does not venture far out into sea, during her stay on shore, if only her young one is not dead, or if she is not very young herself (the maternal instinct by young females is very weak). Though this circumstance is conditional and depends entirely on the configuration of the shore and the surrounding depths; if the seals find plenty of food near the shore, they have no reason to go far out. The seals of Behring Isl. go out less into the sea, than those of Copper Isl., a fact that coincides with the configuration of the shores and the depths near the rookeries. Only part of the effective number of fur seals go on to the shore and remain in the rookeries; for this latter circumstance a developed, sexual instinct is required, which with the seal appears comparatively late; groups of such fur seals (a mixture of young males and females) are found far from their dwelling-places, to this number must be reckoned males and females, who have finished their sexual life; they also go shorewards, emerge for recreation, but do not stay long in one place the bachelors); but the young females generally come towards the shore and climb on to it, when the harem-season is finished (at the beginning of August).

The earliest appearance on the Commander Islands of bulls with the growing up bachelors is stated for the 23 April; the latest departure of seals is at the end of November. In very calm and warm winters groups of seals are seen on the water near the Behring Isl.

The name of "rookery" is accepted for the place, where the seals congregate on the shore. From gear to 
year the groups of seals only occupy specified places along the shore. It has been noticed, that bulls prefer to reside on the same Island, but the place they occupy from year to year vary. On Behring and Copper Islands fur seals appear almost simultaneously, but the arrival in large numbers occurs later on Behring Isl. the arrival on the southern rookery of Behring Isl. is also nearly always one month later, than on the northern rookery of the same Island.

The reason of this is an entirely physical one; as a thick layer of snow is noticeable on a photograph taken at sud. rookery in July month.

The places, chosen by fur seals as rookeries on the shore are varied; either they are shallow, stony or sandy, as it is frequently the case on the northern rookery of Behring Isl. or a steep stony, narrow shore, as are most of the rookeries on Copper Isl., but in all cases, they must be protected from the splash of waves;- the latter depends either on a long distance of shallow-water or on the existence of a barrier far from the shore, which serves as a break-water. The latter is the most favourable one, because between the shore and the barrier there is a considerable space of water, where the newly-born lie safely in the water and learn to swim and when wishing to rest they climb onto large stones. On the photographs of the Palata (Panorama) rookery, taken when the waves were calm, one can see, that there is no harem, where the wave dashes direct on to the shore and that the harem is assembled on the shore, protected by a row of stones placed along the shore. The photograph of the northern rookery and of its different parties, gives a good idea of the locality. The northern rookery composing shistous conglomerate layers destroyed by the action of water (snow) and wind. Conglomerate layers, consolidate with a coloured cement. On places, where the seals dwell the conglomerate is smooth, on the borders it rises above the water forming separate rocks, which 
project far out into the sea; the submerged reefs and separate stones almost surround the rookery. The unimportant part of the rookery is at present seldom occupied by seals, but about ten years ago it was always covered with them and consisted of down-trodden sand, which was produced by a destruction of sandy layers, which. were close to a conglomerate layers (Fontanka). These sandy layers, are joined to a plateau of transformed schists. In the Doubovoi bay the layers are joined on the basalt. The whole shore, starting from the NW cape to the Joushin cape, and from thence to cape Wachsel, is covered with submerged rocks extending into the sea to a distance of 2-4 geograp. miles. This space is thickly overgrown with sea-weeds and serves, as a splendid seal ground for seals. The Poloudennaya rookery and the part of it, that extends far out under the water consist of transformed schists cut by vertical splits filled with quartz. The character of the shore occupied by the fur seals is various, but the important condition for the existing of rookery is, a space of water, protected from the waves break. About 5 miles from the north of the Poloudennaya rookery the character of the shore is different, the coast gets broader and the mountains recede. The beach changes from a stony into a sandy one.

The space between the submerged rocks and those above the water are called boulounki by the natives,- - a dwelling place and refuge for many kinds of fish. The fur seals of the Poloudennaja rookery go northwards to feed-they do not hurry towards the south-the locality acquires a different character. The mountains near the shore finish off very steeply; the shore is broken into by shallow bays with open entrances, which admit a swell. The mountain-chain gets narrower and is cut by numerous narrow splits (deep valeys).

The whole shore is covered by round pebble-stones.

Towards the S. E. cape the mountains break off, precipitously towards the sea. From outward appearances 
the rookeries of Copper Isl. bear a peculiar character, but the water-spaces, protected against the break-waters existing. Copper Isl. is much narrower than Behring Isl. the declinity of the mountains are steep and do not form terraces, set off into the sea; the sea shore is narrow, principally stony and only in some places sandy. The fur seals repose on a narrow beach, causing the rookeries to stretch out in a narrow strip for many miles, intercepted by jetty of the mountain-chain.

The fur seals are obliged to climb up high on to the shore between the rocks. On photographs taken from mountains one can see the stony ground uncovered by the tide. The only comparitively broad strand for rookeries-is that of the Korabelny cape, so called Stolbi, where the sea has destroyed layers of conglomerate, leaving a separate post standing and a broad smooth shore. It must be explained, that late in autumn and in winter, when storms begin and cyclones pass over the Islands and near them, the waves dash against the shore and according to the photographs the waves beat higher than half way up the post and single sprays touch the very top of it, which is covered with vegetation. All along the western shore of Copper Isl. there are submerged rocks, forming an entire barrier, densely overgrown with sea plants, preventing boats from passing in some places entirely impassable through sea-weeds. Seals find food here in abundance not having any competitors in the numerous flights of sea-birds. The sea-otter keeps near the boundaries of the fur seals rookeries, appearing only in the sea near the rookeries after the departure of fur seals, then the sea-otters spread along the whole shore. The different kinds of places for rookeries on Copper Isl., as shown on the photographs, depend on its geological construction, the same as on Behring Isl. The rulcanic activity is more noticed on Copper Isl., where in some places (f. inst. near Palata) the layers are placed in an almost vertical position. The process of destruction 
caused by athmospheric agents connected with the cracking of the layers in vertical, as well as in horizontal way give a beginning to landslips, which crush whole rookeries. Fortunately such large slips seldom occur. Every spring stones begin to fall, partly rolling into the sea and thus building those submerged rocks, mentioned above. The falling of large stones is accompanied by sounds, which remind one of distant shooting. The drives on Copper 1sl. is one of the most difficult; one is obliged to draw the seals up to a height of $600-900$ feet. To form an idea of the steepness of these slopes one must imagine, that drives are accomplished in places, where the breadth of the Island is only about 6 versts, a verst of which has to be deducted on a slight incline. In some of the seals dwelling-places, which are inaccesible, one is obliged to let oneself down on a 2 inch ropeladder and to climb up the same with the skins, taken off the captured seals.

On the Commander Islands only so called bachelors-males from 2-3 rears of age, are killed for the sake of the skin. Males of 4 years-half bulls are only killed occassionally, as single specimens. Females are not killed at all. In the trade there are also some skins, but in very small quantities of those females, that perish during the time, when they were driven away by a sun stroke or were crushed by masses of males, tumbling over them.

An insignificant number of females perish through wounds they receive from the males, when they arrive on the rookeries. The real loss of seals on the rookeries is not important, especially in comparision with the loss of those on the Prybiloff Islands. The greatest loss falls upon the newlyborn, so called black seals, which perish in the harems crushed by bulls, a small number is occassionaly crushed during the time the seals are driven accross, when the bachelors settle down between the spaces of the family divisions; a part, the greater one, of these black seals "Kotiki", perishes after the death of the 
mother, who is killed in the sea by foreigners, during the time, when she is searching for food, and a considerable amount of these females are killed on the boundary to a distance of 20 miles from the shore-the smallest quantity of females is killed more far off lllnes and death occur through parasites Uncinnaria, as it happens in immense portions on St. Paul's Isl. but is not noticed on the Commander Islands.

Every autumn from 200-60o grey seals perish through storms and are washed on to the shore. Grey seals is a name given to seals of a faded black.

The number of seals caught now are a $1 / 4-1 / 6$ of the quantity received of the end of the eightieth years of the XIX century. The general number of herds in comparison with the former time scarcely attain 1/10 part. A more intense killing exists now; all rookeries are exploited, not omitting any divisions, as in former times. The raison d'etre, which at first does not appear to be very normal explains itself by the fact, that before the appearance of pelagic sealing or the opening of it along the shores of Japan, it was possible to have a correct economical account of the killing with the calculation of an annual increase of the animal, as is proved by the figures of the existing killing. With the appearance of an organized pelagic sealing on Asiatic seals in the open sea and near the shore of Japan from February to the end of August one was obliged to cease all calculations, as it was proved, that all propositions made for the benefit of pelagic sealing were never justified and the pel. sealing went on ahead crescendo until suddenly the number of herds decreased so much, that it was necessary to limit the number of vessels, as it was too unprofitable. The stoppage of the intense pelagic sealing: very soon had effect on the quantity captured on the. Islands and it increased slightly. These favourable conditons are threatened by the activity of the pelagic sealing by the Japanese. The Japanese Govermment pay 
a subsidy for sealing-shooners, it is feared, that the sealing will decrease to a greater extent than formerly. Japanese never refuse anything, are satisfied with the smallest earning and besides this at the present time the herds are too insignificant in number to withstand such severe capture by the increased quantities of sealing vessels $\left.{ }^{*}\right)$. The symstoms for a future decrease of the sealing.

Photorgaphs of seal-rookeries on the Commander Islands represent on separate, as well as on panorama copies on several plates-whole divisions of rookeries in all their unity, as characteristics of the dwelling-places, as well as for a better acquaintance with their quantity. Besides this there are potographs of separate family divisions, where on the first place one may see in all its glory, the head of the harem -the bull. On the photographs one can see, how densely these dwelling places are covered with animals, also the number of harems. This density is now very scarce-the harems are not large-their favourite ideal being 15 females to one malc. On the photographs are taken single instances of killing, also groups of females left free on the northern rookery, which is occupied as soon as the bachelors are driven away.

There exist very few printed works in the Russian language, regarding the sealing on the Commander Islands, besides which they are old ones, such as those articles, written by N. Grebnitzky and Waloshinoff are very superficial as those by Dr. Slumin. But in consequence of the activity of the United States, there an extensive literature exists in the English language, which are in connection with the reports of the English par-

*) Those rapidly disappearing seals on the Asiatic, as well as on the American shore may be reckoned to the number of di-appearing animals.

One naturalist even spoke of his conviction, thaf the pelagic sealing only hastens the natural dying out of these animals. 
liamentary commission and of those naturalists, who visited these Islands. One of these works, of Dr. Steinegr is splendidly illustrated and is now being translated into Russian and will be published by the Ministry of Agriculture. The Imperial Academy of Science has long since given up equipping expeditions for studying our land and such ideal places for naturalists as Kamtchatka and the Commander Islands will most likely have a long time to wait still for explorers. To persons interested in seals, one may mention the valuable work by David Starr Jordan with his numerous fellow - labourers under the title of: The fur-seals and, fur-seal Islands of the North Pacific Ocean.

En hy dris 1 utris. The sea-otter is reckoned by lear. ned men to have belonged (already for some years) to the number of disappearing animals, and thus on a full foundation. The extermination of sea-otters began in the middle of the XIIII century and is actively continued up to the present time. Man alone is guilty of its extermination. There are places, where sea-otters used to live in great numbers, they were twice extirpated in great masses, but afterwards in consequence of precautions taken, a small number, which were saved from being extirpatedmultiplied, make it possibility to catch in nets about 200 animals every year without affecting the herds. This is Copper Isl. of the Commander Islands. The naturalist Steller - from Behring's expedition the latter died on this Island and in his memory it was called the Behring Island)-exported above 700 sea-otter skins, while the whole crew lived upon sea-otter and sea-cow's flesh. The Russian traders rapidly extirpated the seaotters on Behring Island, who took refuge on the inhospitable Copper Island, where they were also exterminated. In $1763-22$ years after the discovery of the Islands, instead of exporting a thousand skins only 20 animals were caught. In the interval of trade up to the time of the starting of it by the Russ. imer. Co. the sea-otters 
succereded in increasing and in the twentieth years of last century Behring Island produced about 200 sea-otters; but this was the last considerably large quantity, the sea-otter disappeared on the Islands; it again appeared in the seventieth years on Copper Isl. where strong measures of precausion were taken against the attempts of the natives, as well as of those of foreign pirates; until they succeed in having an annual capture of 200 sea-otters. Such a system of protecting the sea-otter should be recommended to all kingdoms, in whose boundaries sea-otters are found.

Here is another example of how easy it is to extirpate the sea-otter (who except in extreme necessity) swims across the Ocean and serves as an example to the Prybiloff Islands. Here for instance in the first year of their discovery-5,000 sea-otters were killed, in the next year about 6,000 , but for owing to this after 6 years and until now the sea-otter has disappeared. The main dwelling-place of sea-otters, also formerly was the shore of north America and the Aleutian and adjacent Islands, where however the number is still small. At the end of the XVII century I20,000 skins were exported from Prince William Sound and Alexander Archipel near Vancouver. There were ressels killing up to 2,00o animals. Small ressels from Okhotsk brought from a royagt of 5-7 years along the Aleutian Strait a capture of $2-7$ thousand sea-otter skins. At the time of the formation of the Russ. Americ. Co. the number of seaotters decreased so much, that in $\mathrm{I} 804$ out of all the places explored by them, only 15,000 sea-otter skins were exported; in the following years up to 18 fo there was a continuation of sererity, with the result, that there was an entire disappearance of seateotters on the Mentian Islands, then there were precations taken of omitting auptures in some places for years, by which time Mlaskat and the Aleutian Jslands were given over to the Russ.Amer. Co, and they exported every year from 6oo-800 
skins: but it made provisions for the future, the Americans made use of this increasing trade to 6-8000 skins per year (I880-I88I); this was the reason why towards the end of the century the thousands turned into hundreds. The Aleutian Islands, the nearest to our dominions, lost their sea-otters entirely. On the boundary of Russia the Kamtchatka sea-otter was extirpated, but appeared again some years ago (a new-comer from the Kurile Islands): measures are taken in view of prohibitting the killing for three years; but this measure with the exception of protecting the sea-otter on the Kuriles will not be of any benefit.

On the photographs are shown the principal sea-otter dwelling-places on Copper Island near the N. W. cape, the $\mathrm{N}$. W. cape extends in the shape of a high border (consisting of separate sea-otter rocks) far out into the sea; the shore along both sides of the cape form deep bays. The bay on the western part of the Island finishes off with the Red cape, stretching far out into the sea, as a stony border. The entrance into the bay from the $\mathrm{N}$. Western side to the Red cape is surrounded by a broad bank, overgrown with sea-plants, during the daytime the bank covered with weeds, is the farourite place of sea-otters, the bay itself with the sandy beach is deep, as well as the passage to the Red cape. On the sea-otter rocks and the shore of the bay near the Red cape, the sea-otters remain for the night-and this is, what the natives make use of by putting up nets in the sea-otters way. The nets are fastened to the sea plants and kept up by anchors. The beach of the sea-otter rocks and the bay, which in summer are entirely protected against waves and are occupied by females, who feed their young ones. The sea-otter requires its mother's care for a very long time. The place indicated is the principal dwelling for the herds of sea-otters and convenient for feeding and bringing up their young. The increase of sea-otters made them look out for new places and ther began to 
settle along the western coast, which by its natural conditions is the most favourable one. The increase in the number of sea-otters, made it difficult to protect them, there are not sufficient people to guard rookerys for $2^{\frac{1}{2}}$ months during seal-hunting season, a very important item to the natives. This same scarcety of people forces them to try and prevent sea-otters forming a rookery on the S. E. terminus of Copper Isl., as there are favourable conditions for doing so in consequence of the population being settled at a remote distance, this becomes even more complicated by the fact, that in the neighbourhood there are no places, where it would be possible to place a guard. One must hope, that such a valuable animal will incite the Government to take upon itself the expenses for a floating guard (a steamcutter with a deck).

The sea-otter keeps near the shore and it is not difficult to protect it, if there is only the wish and means to do the same. At a distance from the coast the seaotter can only be found on large banks overgrown with sea-weeds, where there is no sea-weeds sea-otters do not dwell; but the existence of these sea-weeds, which grows only in a certain depth gives the above mentioned character to the shore and to the sea-bottom.

Besides the capture with nets on Copper Isl. in stated places on the shore, regularly once in ten years in winter time a sea-otter capture is effected for the purpose of excluding those old males out of the herds, who hare finished their sexual activity and are hindering the young males. According to statitstics the sex of sea-otters on Copper Isl. is not very favourable-the quantity of fematles is only somewhat larger, than that of males. But this state of sex is still more unfarourable in other places, where the number of males predominates. The increase of the herds is considerably a slow one, as the female. only becomes fruitful at the end of her second year and has only one young one at a time, which she feeds at long time. The time of sexual maturity and sexual desire 
shows many individual inclinations. The birth is not appointed to a certain date of the month, but lasts from 3-6 months. Generally the herds, led by sexual inclination begin to assemble in March month and remain for three or four months; after this time the herds begin their departure; the state of the weather has a great influence on the herds assembling later or sooner. The structure of the shore where the sea-ntters stay, has an influence on the value of the furs. Very stony, also rough places (as on the shore consisting of small conglomerate or coarse sand) produce furs with the hairs rubbed off on the stomach part, a sandy shore produces sea-otter furs with short hair on the back too. The female has the best skin as regards the colour, length and softness of the fur wool. Best furs on the Commander Islands are taken in March, April and May. The hair casting is partly in July and August. The summer sea-otters are the least valued. The first casting of hair after birth sets in after 5-6 months; the proper hair with the caractiristic underhair the sea-otter acquires towards the end of its first or the beginning of its second year. Sea-otters, that are from 2 or 3 years old, have the best hair.

Sea-birds, who choose the Commander Islands, as the place for breeding are there in innumerable flights, though by far not as many as in the north, on the rocks of birds. The Islands lay too far southward. In this cold damp climate, there is no possibility of getting guano. The exploitation of the riches of birds is no more tought of by the natives, than in making use of the flesh and eggs. Feathers and down are only used for the real necessities of the people, generally they are thrown away together with the skin. Making clothes out of bird-skins is no more practised. The natives prefer birds with a lot of fat and a peculiar taste. The number of different kinds of seatbirds, constantly living on the Islands, is not great. Some species of sea-gulls, two kinds of cormorants, Simorhynchus and Sypttiliboramphus are known by the name of 
owes old stagers. The Islands are chosen for nestle by the following kinds, such as sea-gulls, Alcidae: sea parrots etc in small quantities Oceanodroma Procellaria. In winter several species of ducks. The Mainland is used to nestle, by a great number of marsh game (above 30 species of ducks and snipes) some swans and geese. To the constant inhabitants must be reckoned, such as eagles, falcons (three kinds), mountain partridges. The absence of woods explains the scarcity of different species of singing and other birds etc. There are some kinds of birds, which belong exclusively to the Behring Isl., the majority are crows Corvus beringianus. The nearness of the Mainland and the Aleutian Islands affords a great number of strange birds to come and nestle there sometimes and by mistake are driven into the faun of the Islands. The birds on the Commander Islands proved to be the best known of all other parts of the faun.

The fish-riches of the sea, surrounding the Commander Islands, require some one to undertake this industry. The Americans, who occupied themselves in the sixtieth years of the XIX century with catching cod-fish, left this buisiness after the Alaska and Aleutian Islands went over to them, and on these places they concentrated their activity. The natives did not make any other use of the fish-except for their own consumption.

The cod-fish is usually of the same kind, as those that are found on the shores of Europe and America, namely the Gadus morrhua. The traders sort them into several classes, they differ by their general outward ap)pearance (large-headed, big-bellied etc). Another kind of cod-fish is the saïda, belonging to occasional visitors and they do not go in considerable numbers berond the bounds of floating ice. On the photograps both kinds of cod-fish are represented. Gadus gracilis and G. chalcogrammus are rare visitors.

The halibut is of a little importance, as there are very fere of them and most likely they advance towards the 
southern boundary of the Commander Islands. In deep waters (60-Ioo fathoms) the halibut is found in greater quantity and of larger size, but fishing in such depths requires special arrangements. As the markets are so near, where fresh halibut is sold, as well as a simular kind of fish called the Hippoglossoides, which have tasty flesh, they ought to serve as a good object for trade, but when salted the fish loses its quality and only satisfies a very uncultivated taste. One may say the same about the numerous specimens of flounders (Platessa).

The specimens of the Chiridae class are characteristics of the faun af the Pacific in their numerous species and are of important economic value to the inhabitants of the shore, as well as to the sea-animals. The Hexagrammus monopterygius $\mathrm{L}$. and $\mathrm{G}$. is canned in large masses on the Aleutian Islands and is known in the American markets as Arctic mackerel, reminding of the real mackerel by the taste of its salted flesh. The time, when this kind of fish appears in shoals near the shore coincides with the time of seal-killing and therefore the natives of the Commander Islands conserve same for themselves in a small quantity. The other kinds have only a local signification.

The specimens of Sebastes and Sebastodes (see photographs) which give excellent flesh may in the future attain a small importance in trade, as they are delicious, when canned.

The different kinds of Cottidae, many species of which and the majority belong only to the $\mathrm{N}$. part of the Pacific and have a considerable local economic value, serving as food not only to man, but also to the sea-animals. On the photographs are shown only members of the species Hemilepidotus and one kind of Cottus.

Of great importance to the codfish are the members of the families Trichodontidae and Trachinidae, as well as Cyclopterychtis, Arenaria and g. Nallotus; - the coming of the cod-fish towards the shore depends on the 
appearance of their herds. Besides this they produce the best bait for cod-fish.

The specimens of the fam. Agonidae, Liparidae and Blennidae besides being of scientific interest serve as food to Chiridae and Cottidae. Of the latter family the seawolf (Anarrhichas) might be of particular importance, but it multiplies in very small quantities and besides it could scarcely be an object of trading, as there are so many more valuable species to be found. In regard to trade the specimens of Salmo are of the greatest importance.

On the Commander Islands one can find nearly all representatives of this species belonging to the Asiatic and American shores, but as regards quantity and economic signification the first place belongs to the red fish (Nerka).

Its flesh, though it has not any particular taste (as for instance the king-salmon), is preferable for canning, as well as for salting. The redness of the flesh (a deep red) does not lose its colour after canning; the delicate coloured (with the exception of the silver salmon) flesh of other fish lose their colour after, an item that is greatly valued, especially by the consumers-the Anglo-Saxons. In salt the flesh of this species keeps better, than any other species. On photographs we see fishes, that only just leaving the sea for the rivers, as well as those that thrive in rivers. The confirmed opinion of Middendorf, that the fish Salmo coming into the rivers to spawn (Todtrandern) are sure to perish-according to observations on the Commander Islands is only partly correct; the young thriving fishes float back into the sea. Behring Isl. presents an ideal place for biological observations for the breeding of salmon. The arrival and thriving of red fish begin by much sooner on the Commander lslands, than on the east shore of the Kamtchatka peninsula.

The local population prepare the fish in a dry and dried up waty, the damp climate does not permit a good produce. The fish is salted very slightly, as the natives 
do not like salt-fish. It is prepared as food not only for men, but also for dogs; lately they have started preparing fermented fish for dogs in holes.

The silver salmon Onc. Kisutsch in regard to the quantity of fish caught takes the second place. Its flesh is also considered very good for canning and salting. It comes to the Commander Islands in August; the principal time for spawn is December month. On the photographs are shown the spawning forms, as well as those Kisutsches, that only come from the sea, and young fish, which after spawn float back into the sea.

The Keta, is of economic importance to the Amour and is not an insignificant part to play on the Kamtchatka peninsula, where it is called Haiko and is prepared during the years of famine (by natives).

But for the Japanese markets it is prepared in great quantities (in dry salt). It does not spawn on the Commander Islands and only is found in single specimens. The king Salmon-Tchavitcha play an important part, being the largest, at the same time the most tastful nember of this species. It is good for canning, but in salt its tender, fat flesh does not keep long and loses its qualities, it does not keep long smoked either. It does not spawn on the Islands, as it only comes-singly. It is the first to go into the Kamtchatka rivers.

The Humpback salmon thrives on the Commander Islands, but in small quantities. It is liked as food, t.ut is not prepared for keeping. It is rarely used for canning, giving valueless produce.

Salmo purpuratus, which appears in autumn and winter for spawn, serve as a deputy to the inhabitants by giving them sweet flesh at such a time, when salmonfishing ceases or decreases to a nonentity. This laketrout's flesh has a different taste, which depends of the water, where it stays (that is its food). On the Commander Islands it is called Baidarstchic (sealskin canoe owner) or the master of the river (chiranum toukoukt) its flesh is 
Lasty, near the shore of Kamtchatka it is comparetively a rare, but tasty fish.

Salmon-trout (Salvelinus malma-mountain-trout) is one of best tasting fish on the Commander Islands, thrives in any basins and has several kinds of varieties. To attain sexual maturity it floats into the sea-appearing in the rivers at two periods, in spring and autumn. On the photographs are shown adult specimens going into the river. In the rivers the mountain-trout is subject to a change of form, whereby the head remains the same, but only the colour of the skin changes and pectoral and ventrals fins develope in width. During the whole of its stay in the river until spring this trout feeds on various shell-fish (with the exception of Mysidae) and its flesh acquires a peculiar taste. Feeding on Hammarids and ostrakods gives a less tender taste to the flesh. The photograph gives one an idea af the outward appearance of the river-trout.

Amongst the other specimens of the SalmonidatMallotus villosus Cuv (Capelin), had an important value on the life of the cod-fish. On the Commander Islands there are not many of these or other members of this class; Osmerus are rarely washed in by the sea together with the herring which passes the Islands in shoals, but never spawn here.

Here just like in Europe great quantities of sticklebacks are found in the sea, as well as in rivers. This small fish does great harm to the roe and to the young salmon, the Americans have correctly called it the salmom killer. On the Commander Islands stickle-backs has no economical value as food. On the eastern shore of Kamtchatka, during the years of famine it is prepared together with some species of Osmerus (O) ouek in northern part of Kamtchatka).

The members of the Raja species afford only a scientific interest as the specimens of the shark; the last occasionally appear in shoals near the Islands. 
The ichtiological fauna of the Behring sea is comparitively well studied, but unfortunately it is only the shore fauna; the fauna in the great depths has yet to be studied.

The shore of Kamtchatka has only just been started to be explored, to say nothing of the more northern parts. The existing deep-ivaters already explored are only made by Albaftross and the chiefly refer to that part of the Behring sea, which is nearest to the American shore. The American shore, beginning from the Californian Gulf, as far as the Barrou cape have been minutely explored.

No extentive work exists of Kamtchatka, since the time of Pallas; American naturalists occasionally found collected material, as well as also for learned Russians (Herzenstein's labour was not finished).

As charactiristic of the sea near the Commander Islands molluses must be mentioned. The existing works of Russians, as well as foreigners about the mollusc-fauna, giving the description of mollusks found in the littoral and laminar zone; occassionaly dredges were placed to a depth of 30 fathoms or more (Vega). The characteristic of the water round the Commander Islands is, that it contains very little lime (calcareous salt) and the result of which is the compativelly thin shell even of large species. The forms of other classes of animals, that require lime (lime-sponges, rhizopodes) are represented in a small number of ways, but forms requiring silex are plentiful. The number of molluses species is not large, but the existing species are shown in great individual quantities. As for extensioness and quantity the Mytilus take the first place, the remainder of which lie in heaps on the shore and form considerable masses in the sand-hills.

This is good food for the natives (in a raw state), also for a quantity of sea-fish and sometimes animals. Then comes the Mactra Grayana, which does not attain such a large size, as in the Okhotsk sea and the most northern Islands of the Behring sea. The natives only make use of those, that are washed in by storm; the rest of the Mactra de- 
cays, together with Siliqua patula (Machaera costata) giving the material for sand-hills. The latter molluse is noted for the thiness of its shell in comparison with those of the Okhotsk sea. The flesh of this mollusc might be canned. The young ones of these molluscs are a favourite food of the cod-fish, the adult ones together with other molluscs are eaten by sea-otters.

That the life on the sea-shore has changed is proved by the disappearance of two kinds of Cardium, which are in the waters on the Islands; they are found in pieces in the sand-hills and at a distance from the sea-shore near the mouth of rivers, which flow into the Gavanskoye lake, which was formed out of a former sea-gulf. Along the shore of Kamtchatka this species also exists; on Copper Isl. they are rarely found washed in by the sea. Two other kinds of Cardium are remarkable for smalness and thin shells.

There are two kinds of stone-fretters found, the Saxicava and Pholas, the latter are found in the rocks at a considerable distance from the tidal wave and proves, that the shore is raised. On Behring Isl., such facts are also known about the southern part of the Kamtchatka peninsula.

The various kinds of Tellina and Venerupis on the shore (at the foot of the sand-hills), are the means of building the sand-hills, in places of fine pebble-stone they are cemented to the latter (doubtless on the shore, at a distance from the break-water).

Specimens of the g. Mya (M. arenaria and M. truncata) are found in small quantities; on the American shore they are canned.

There are no oyesters either on the Commander Islands or on the shore of Kamtchatka-they are replated by Anomia ephippium and are not used as food; having a taste of copper (the spots on the interior of the shell are of a green colour).

The remaining biralva molluses are only of scientific interest, as they are only inlabitants of the Commander 
Islands, are of no practical value (Panopaea norvegica; Pecteniseandicus g. Modiolaria and others).

The specimens of the Chiton are characterictics of the Islands and are now divided into many independent species and sub-species, they attain immense sizes, as the Chryptochiton Stelleri. For their immense size are also noted the inhabitants of the sea-weeds, such as the Aeolis, Doris, Thetis and others molluscs of this order.

When the tide is out, all the stones are occupied by specimens of the g. Littorina (several different species), one can actually not put one's foot down without crushing a lot of molluses. They are eaten by the people, but mostly by the fish. Large specimens of the L. grandis are seldom found. From the boundary of the tide numerous specimens of the Patella and Acmaca species are found and in summer a no smaller quantity is to be found in the same places of Buccinum (ovatum tenebrosum, ovum and others), Margarita (in sea-weeds), Purpura Freycinetii. Patella men use for food, the others are consumed by the Hexagrammus, Hemilepidotus and sometimes by the cod-fish. Natica and Fusus (antiqua) are found in great quantities, but are of no importance.

The Gonatus amoenus play the greatest part and their young ones are washed onto the shore in heaps (on Copper Isl.) and are the favourite food of fur seals. The Gonatus amoenus is one of the pelagic species. Members of the g. Octopus of enormous size are seldom eaten by fur seals, but chiefly by sea-lions. In spring and summer the natives catch them under the stones (they begin in February), these people call it a button-crawfish and is a dainty dish to them (of course it is raw). The young ones are greedily extirpated by the cod-fish. The other specimens of this class the g. Onychotheutis (Lestoteutis) are of no economical value, but attain an astonishing large size.

The Terebratulidae are a very insignificant species. and are rarely found. 
The molluses of the Commander Islands are described by the American naturalist Dall (77 kinds according to the latest articles in I899) a list of the molluses of the Commander Islands, was given by N. Grebnitzky.

The earth molluscs have a very thin shell (Limax and Arion are very rare).

The craw-fish fauna notwithslanding its economical importance is very unsatisfactory explored on the Commander Islands; the decapoda are studied, slightly but the most important groups the Amphipoda, Isopoda, Ostracoda, are not spoken of at all; with the exception of a few accidental definitions. The existing collections are waiting to be elaborated. Of the small forms, for instance the Copepoda is nowhere mentioned and is especially important for the plankton. This item will most likely not be finished for a long while yet. The study of it must absolutely be done on the spot, but the existing literature is so extensive and expensive, that it is too difficult for any observer. But the naturalists visiting the Islands did not attend to this species and solely occupied themselves with the vertebrata. But how interesting to science this class might become, is proved by Tcherniarsky's small work of Mysidae. In speaking of the parasite craw-fish species, only the parasites of whales are mentioned.

Large decapoda are not found on the Island and they are represented by very small specimens. They are eaten by the cod-fish and the Chiridae. But there are numerous specimens (3) of craw-fish-hermits, also small, which serve as food to the fish near the shore. The sea, as well as the river Mysidae come in shoals and in the rivers they are eaten by the trout, in the sea mostly by Batymaster, which again are good food for the cod-fish. Of crevets, there are no less than 8 species shown, which are also eaten in quantities by all sea-fish.

Of the small Isopodat the Mumna and Yanira species are found near the beach; the larger ones, such as the 
Cirolana and others go into the depths and up to the present time it has only been possible to notice those forms, that stick to fishes. It is interesting, that lately the earthy form Oniscus is brought from Kamtchatka.

From the Amphipoda only Gammaridae and Lysianassidae are of any importance as food for some fishes; the other specimens (rather numerous in species and form) are of no importance, though they nearly all serve as food for young fish and small kinds of fish. But there exists no systematical definition.

Some fresh water forms Entomostraca collected now and again, are stated, but there is no information, as to their spreading and quantity. The fresh-water plankton, which has been collected by me, is not yet determined.

The fairly large sized Branchipus (of the Phyllopoda) was not reckoned to number of fish food.

In consequence of the great importance of the Copepoda in plankton, the salt, as well as the fresh water ones are not studied at all. On may judge of their great number by the immense spaces of sea-covered with white stripeswhich are formed by members of this class. Parasiticforms of Copepoda are not studied even to the present time.

The Cirripedia are not described at all, but they are (with a few exceptions) of no importance as food for fish.

An important food for the young fish is the larva of mosquitos and other water insects. A splendid collection of insects (unfortunately the majority are coleoptera) is now being worked upon.

Chaetopoda though serving as food to young sea-fish, also not studied, nor the collections of sponges either. The only ascaridae, that has been studied as the parasite of the fur seal. The Echinodermata the Echinus neglectus is of importance in the sea-otter's life; the young ones serve as food to many fishes. Out of the numerous specimens of sea-stars only the small species Ophiuridac are of importance as fish-food. 
A grcat quantity of Holotouriate are found and serve as food to the natives and some fish (not large ones), the small specimens of this kind living at the boundary of the tide, when it is either in or out, are of no importance as food for fish. The Holotouriae might be prepared for Chinese markets.

Colenterata and Protozoa are not at all studied, though the latter are of great importance as food for a mass of inhabitants of the sea.

From land animals only the Arctic fox is of considerable importance in the economic life of the Commander Islands. Photographs give a good idea of this animal. It is supposed, that this fox made its appearance onto these Islands, separated from the mainland, by getting onto the floating ice, which in former times went far more south. Blocks of ice emerging from the bays of the Kamtchatka peninsula rarely appear near Behring Isl. not going further south, than the northern point af the afore named Islands. In former times, judging by Steller's description, they were exceedingly numerous on the Island. The expedition: of Kamtchatka hunters have diminished the number of Arctic foxes, they were saved from total extermination by the Russ. Amer. Co. which at the beginning of the XIX century did not keep constant hunters on the Islands, but only sent out small hunting parties for the capture of sea-otters and afterwards for foxes. In 1826 a resident population of married people settled and regulations were made, as to the quantity and time of year for hunting. This regulation, which is even more severe, is kept up) until now, which appoints not only the order, but also the manner of hunting. The latter is allowed only every alternate year and at a certain time, namely in December. beginning a little sooner on Behring Isl. It this time, when the weather is worst and there is no hunting effected. In January there is no hunting carried on, though the skin is rather satisfactory. In February they begin to pair off. The young one's appear in July; the first fur is shed in 
November and continues until December. The older the fox is, the more valuable the fur. The young ones, which have shed their fur are called half-grown arctic foxes (nedopesok) and have short uneven hairs and are also not equally coloured. The best and most homogeneous in colour and dark furs are from Copper Isl. The colour of the hair varies from light gray to entire black, but the latter are a great scarcity. In the market the furs besides being valued by their size, are valued by the length and colour of hairs, and also the quality of the short wool, which is of different kinds. In spring with the arrival of the flights of sea-birds-the predominating food of foxes, on both Islands birds and eggs appear, though the fox does not refuse anything washed in by the sea. With the departure of sea-birds a hard time commences for the fox. On Behring Isl. it can catch fish in the rivers and hunt partridges yet, on Copper Isl. it is more difficult to obtani food. Here it often finds the leavings of the seals carcasses and frequently visits the shore to search for birds-sometimes a soundly sleeping cormorant (Phalacocorax) becomes its victim-but this is rare, as the cormorant prefers to sleep in places rather inaccesible to the fox, and besides which at that time the rocks are frozen over. But on the shore are always plenty of things washed in by the sea and also sea-urchins, which serve as splendid food, though every year foxes are found having died of starvation. Hunger compels the fox to steal provisions, which are badly hidden by the natives. In general the number of foxes on Copper Isl. have diminished with the decrease of the pelagic sealing now no seal carcases remain, only useless rejections are there, which are allowed to decay. In summer during the time of luxury the fox only eats the breast of the birds, throwing away the rest.

The fox actually eats everything it finds thrown out on to the beach. In its hole, stores of bone's are found, which shows, that the fox brings all it captures or finds to his hole and thanks to this, skeletons are preserved 
(not whole ones) of a species of cormorants, which have died out, from the middle of the XIX century. The general quantity of killed foxes now does not attain 2,000 on both Islands. The reason of this is the decrease of the foxes on Copper Isl. The result will be seen in Igor, as in important places, no fox-hunt has been carried on for four years. This experiment will be the means of judging, how far the decrease of sealing was to blame in the diminishing of the fox herds and whether the reason is not, that the hunt has been too careless and numerous in former times. In winter the fores get so daring, that they go to the villages on Behring 1sl.; on Copper Isl. where no dogs exist, they even live under the sheds. The fox becomes rather tame, if caught when young, but its thieving capacities and the smell from it, does not permit one to keep it long in bondage.

As part of mammalia brought to the Islands, must be mentioned the rein-deer. According to the initiatives of Dr. Dyborsky, who has taken great trouble in studying Kamtchatka and who has written much about the Commander Islands (in Polish), the former Alaska Company brought rein-deers onto Behring Isl.-4 males and I females, where they multiplied splendidly, so that in 1882 they formed a group of about Iooo animals.

At the present time yearly for the administration about ten reindeers are killed. As the same time as the rein-deer, the gad-fly became known.

In General the vicinity of Kamtchatka and the private means of communication have made it possible for several terrestria animals to appear-Microtus rutilus the field-mouse; the house-mouse was brouhgt in in 1870 from America with flour. The bat appared from Kamtchatka (Vespertilio). With wood, coming from Petroparlorsk, many kinds of insects were brought in, as well as with compressed hay from America and Kamtehatkat. The untidy Kamtchatka Kossateks brought with them the indispensable attribute of a Russian hut-the tarakan (black bectle) 
and bug, not more than 30 years ago. (Many plants brougt from Kamtchatka have as yet not spread further, than to neighbouring villages). Lately Kamtchatka has sent women to the Islands, but it has not proved successful.

This experiment has not resulted in success. 


\section{Population of the Commander Islands.}

The fundamental group of the highest of mammalia-the man, was brought in 1828 from the Aleutian Islands Atkha and Attou, in consequence of which, every island received representatives of the same island, in view of an existing animosity between the inhabitants of the different groups of the Aleutian Islands. The Behring Island received the inhabitants of Atkha, the Copper Island those of Attou.

Both branches spoke in dialects of the same language. At the end of the 40 years the Russian-American company began to settle here as pensioners-natives of European Russia; but whether this was a slavonic branch-it is difficult to say, most likely the greatest part were GreatRussians, though to be sure it is almost certain there will have been also some Ziranes, Gipsies and even one Kirgese-woman. The present existing population is a result of the cross-breed of the colonists of these different races. It is owing to the intermarriages between the settlers of these different races that the at present existing population is, what it now is. To this the administration added some Esquimaux (from the Kodjak Isl.) colonists of the Kurile strait, among which there were also Kaloshensky Creoles. Undoubtedly through dying out of this metization there and the idea of making use of Russian descendants from Kamtchatka this experiment proved to be totally unsuccessful as only the inferior element went to the Islands. 


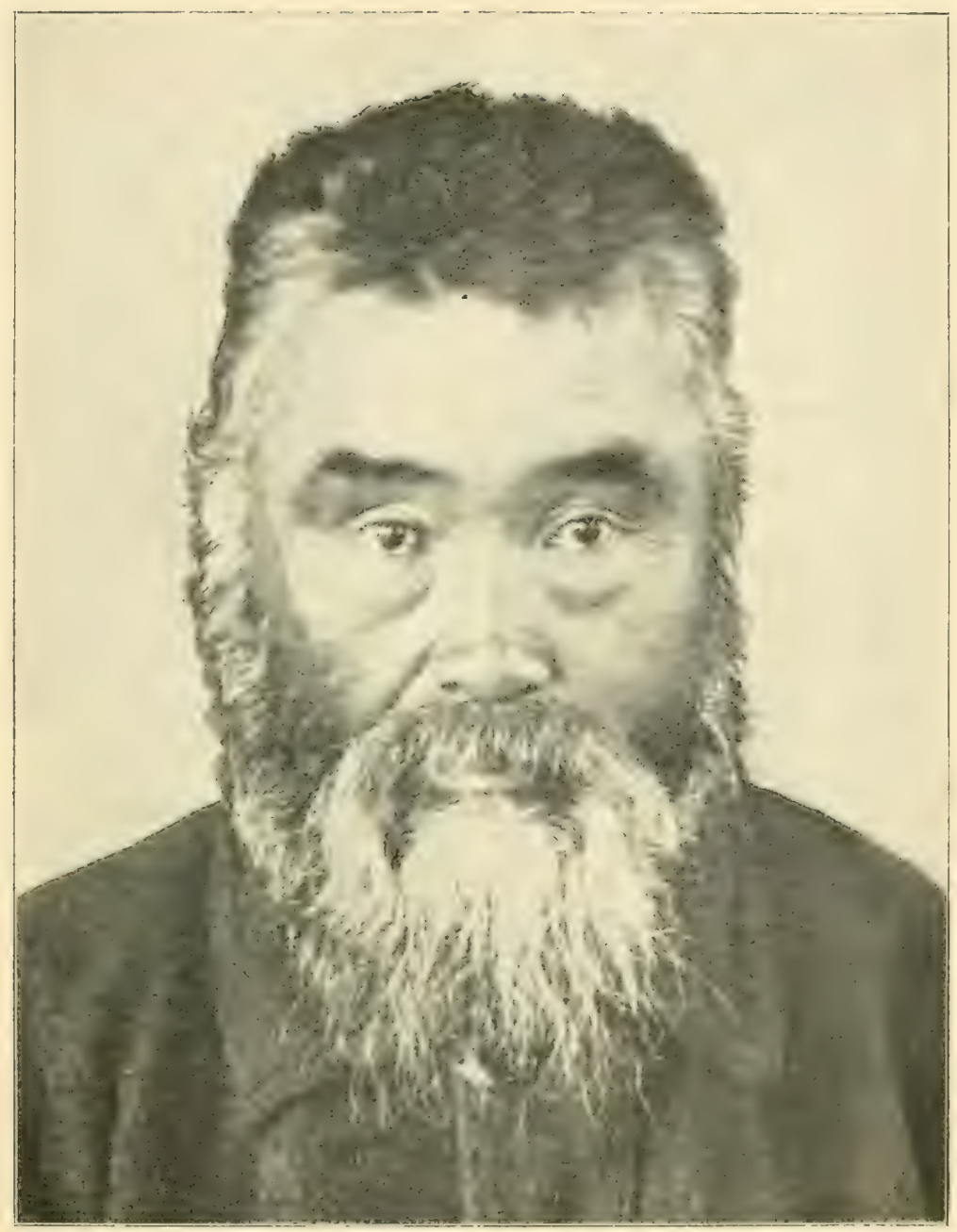

The typical Aleut Simon Stepanoff. 


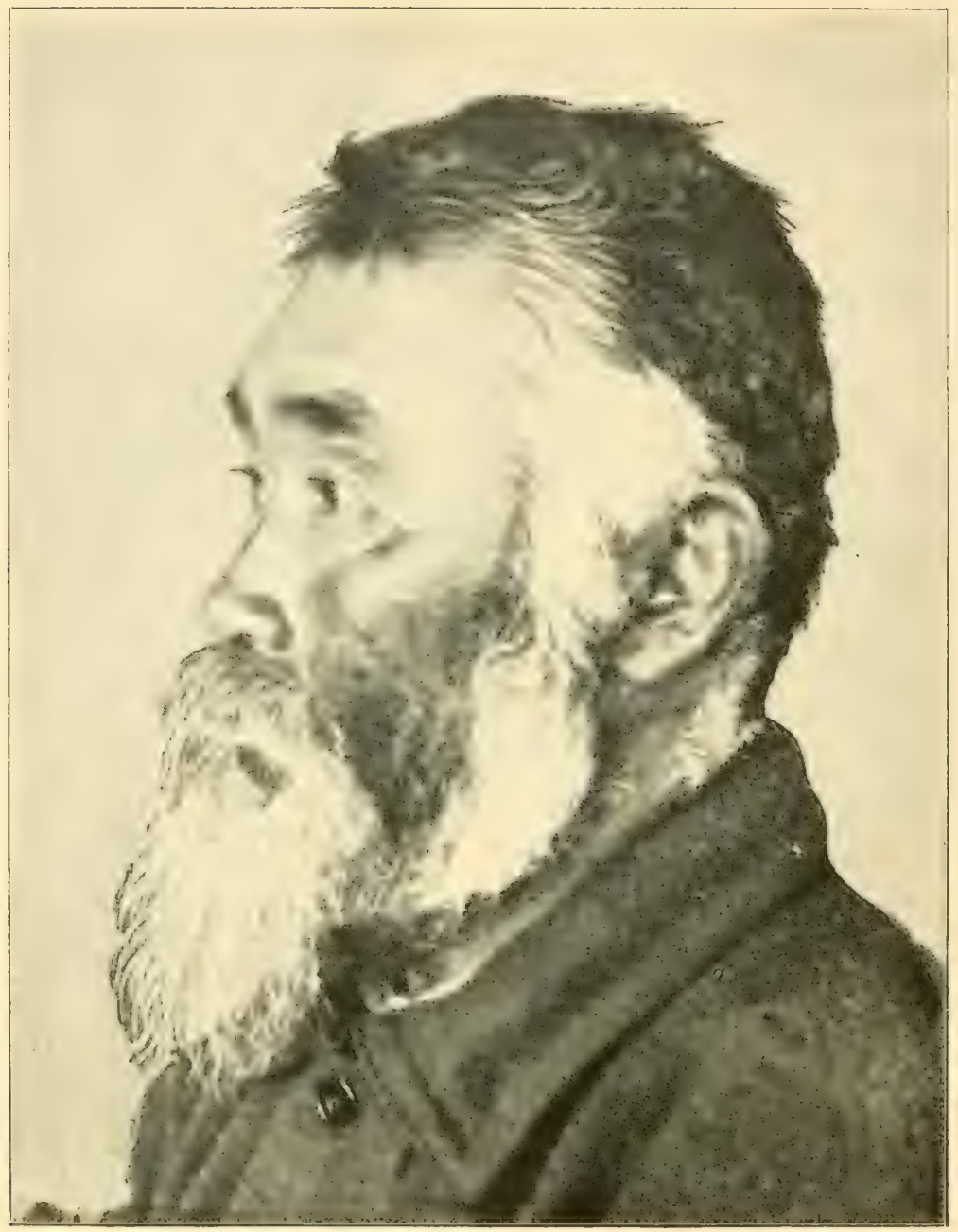

The same Aleut, in profile. 
It is too soon to speak of the final result yet, but the existing population gives little hope of attaining a steady or persevering generation. The pure species of the fundamental group,- the Aleuts has already entirely disappeared and it is doubtful, whether it even existed at the time the adjacent Islands were discovered, as it had without doubt an admixture of Japanese blood from those Japanese, that were (expelled by historians), belong to the Mongolian inhabitants of North-America of very numerous tribes, but who have general autropological features (habits) and the same basis of language (agglutinatives). By fragments of pœtry, narratives and the foundation of the language, one can sketch in general lines, the way the Aleutian stratum was peopled, whereby the new-comers supplanted those, who had settled earlier to the very end of the Aleutian Islands. A further transmigration was put a stop to, by a broad strait (300 miles) separating the Commander Islands from the adjacent Aleutian Islands. Although there are some existing proofs, that the Commander Islands were visited before their discovery by Behring, yet it is difficult to say by whom, as there is nothing to go by, except the discovery of a few arrow points (decidedly of Aleutian origin).

Though from the time of their emigration fron America (Alaska) the Aleuts, or as they call themselves Ounangakh (man) were already acquainted with the use of flint stone arms and the treatment of furs for seal skin canœs and their construction (the construction of the skeleton they have most likely borrowed), but the summit of their civilization was not great, they mere on that low step, which one might call a zoological state. The Aleuts had nothing more than a dart and a most primitive stonehatchet with needles of fish-bone, an angle composed of wood and bone. They did not know the bow, which was brought much later.

They spent their life in looking for food, constantly fighting to get it, the animosity was a general feature 
among these small communities, if a similar expression can be used for the existing conglomeration. The vanquished were made slaves (Kalgi) and forced to do all the work. The scarcity of women brought onpolyandria. Relationship was reckoned from the mother's side. In some narratives we hear of the existence of cannibalism. The character of the Aleut seems apathetic idle, immovable, and very fond of much distraction. Comming in contact with Russians (and on the adjacent Islands near Alaska with many other differend races) the Aleuts have rapidly acquired exterior culture and christianity so, that at the beginning of the XIX century there were very few heathens left (the Aleuts had no worked out systematic religions principles, they were in a state of animism), but the national character remained fully untouched; there appeared an outward submission to the suppression of the master (and very severe ones at the time of the Russ. Americ. Co.) and developped unsympathetic traces of the low servility and flattery. The travellers passing by and missionaries (who had a great influence over the Aleuts) cannot sufficiently praise their sincerity, honesty and other beautiful qualities, wher eas people, who have been infortunate enough to have lived any length of time, amongst the population-write, that of all those, who are subjects of the Russ. Amer. Co., the worst were those from Atkha and Attou.

But this is an extreme opinion. One cannot deny, that the Aleut has a capacity for mechanical labour, but he never attains perfection in it, as also there is little facility for intellectual development; stupidity of intellect is remarkable.

The Aleut is false, vindictive, he will never attack face to face, but always from behind a corner in ambush. An Aleut never forgets an offence and patiently waits for a convenient time to revenge himself.

The population of the Commander lslands with at considerable admixture of foreign blood, gave two types, 
which are shown on photographs taken from characteristic representatives en face and en profile. Not tall, with big heads, belong more to the pure Aleutian type of medium height, seldom tall, the type with small heads. The Mongolia features remained with the whole population in a small degree, which is most remarkable on children. The most beautiful cross-breed was produced by Yews, Trich and Gypsies. The moral ideas of the population are not of a high standard. From an intellectual view they stand considerably high; civilization grows slowly, but what they appropriate is lasting. The foundation of the household in the way as for nationality is the same as those of the Russian colonists, but the private ways and family ideas are not unlike the Aleutian ideas. In general, during my stay for nearly 25 years there, the population has gone ahead in every thing, except religion and sexual morality. $\mathrm{Up}$ to 1898 there was no syphilis on the Islands and now one can consider the whole population to have syphilis. On the photographs every where (according to Broka's system) the degree of metization is marked. There are given photographs of criminal murderers and recidivate thieves. The RussianAmeric. Co made an experiment on the Islands in a small degree by intermingling races, which were far from one another. The result of the experiment proved the admixture attained, which was destined to die out of its own accord, producing an unreliable generation and in some respects an unfertile mixtion. The intermingling of new elements of Aleutian, Slavonic or other blood increases the fertility and gives a more steady generation. This question is worked out principally by myself and affords a subject of special labour. The degeneration of the population is an undoubted fact, resulting in the dying out of it. 


\section{The photographs taken on the Commander Islands by N. A, Grebnitzky.}

\section{Zeiss Anastigmate Ser. III-A \& Ser. VII.}

1. 2. Dog salmon. Haiko. Behring Isld. Oncorlynchus ketr. Lake Saranna. August I899.

3. Ked fish. Blue back salmon. Oncorhynchus nerka. Berhing Isld. August. Female before spawning.

4. also Berhing Isld. September. Female after spawning.

5. also August. Adult male called by natives-loch.

6. 7. also Male and female.

S. Silver salmon. Oncorhynchus kisutch. Behring Isld. Male in August ascending the river.

9. 10. also Male and female before spawn.

11. also Lake Saranna after spawning descendent to sea.

12. $\left\{\begin{array}{l}\text { also Joung male. } \\ \text { also Female. January. }\end{array}\right.$

13. also Female spawning.

14. $\left\{\begin{array}{l}\text { also Aduet male descendent from river to sea. } \\ \text { Lake-trout. Salmo purpuratus. Behring Isld. }\end{array}\right.$

15. Silver salmon. Male and female. November.

16. King salmon. Oncorhynchus tschazvitscha. Behring Isld. july. Length $107 \mathrm{~cm}$. weight 32 pounds.

17. Humpack salmon. Gorbusha. Oncorhwnchus gorbusha. Behring I.

18. also Adult male in river. August. Behring Isld.

19. also Adult female " " "

20. also " male "

21. Salmon-trout. Salvelimus malma. Male ascending in the river Ladiginskaja. $56 \mathrm{~cm}$. 22. also Female ascending in the river Ladiginskaja $60 \mathrm{~cm}$.

23. Salmon-trout. Adult male Behring Isld.

24. Lake-trout. Salmo purpuratus. Behring Isld. October.

25. also Behring Isld. November. Male \& female.

$\because 6$. also October. 
28. Cod fish. Gadus morrhua. Copper Isld. I5 pound.

30. also Boreogadus saida )) 》)

31. Hemilepidotus trachums. Behring Isld. September.

32. also Jordani. " " August.

33. Halibut. Hippoglossus vulgaris " "

34. Flounder. Pleuronectes (Platichtys) stellatus. Behring Isld.

3.j. Rock-trout. Hevagrammus monopterysusus. June. Behring Isld.

37-43. Different species of Hexagrammus from Behring Isld.

44-47. Different species fam. Cottidae. Behring Isld.

48. 49. Rock fish. Sebastodes marimus. Behring Isld.

50. 51. also ”

52. also

53. also Sebastodes sp. Behring Isld.

54. Hexagramus superciliosus. May Spawning Season. Behring Isld. 55. Dolphin. Behring Isld. June.

56. also and Kamtchatka kossack.

57-62. Scull of Ziphins Grebnitzkii (whale). Behring Isld.

63-66. Scull of Mesoplodon Steinegeri. Behring Isld.

(i7. 68. Star-fishes from Behring Isld.

69. Siliciores sponges from. Behring Isld.

70. 71. Walrus. Odobarmus obesus killed I January 1900 in the river Gavanskaja near the village Nikolskoje.

72-7. Different methods of catching (seizing) blue foxes.

78. Drying blue foxes skins. Behring Isld.

79. Blue fox. Canis lagopus.

50. 81. Cattle Herd on Behring Isld. in sand hills.

82. Drying sea-otters skins. Copper Isld.

83. 84. American goose (Aleutian goose).

85-89. Ducks on Behring IsId.

90. 91. Anas querquedula. Behring İsld.

92-95. Snipes. Behring Isld.

96. Prepairing to slaughter. Assorting killable furseals.

97. The killing of for seals.

98. 99. Fur seals females set free from the drive.

100. Newborn fur seals. July I899. South rookery.

101. 102. I Iarems on North rookery. Behring Isld. July r8g9.

108. Harems on Korabelnaja rookery near Spillars.

104-105. Kischetshnaja rookery. Behring Isld. July I899.

106. 107. North rookery. July I899

108. Principal north rookery. July r8g9.

109. South rookery. July 1899.

110. North rookery. Sivutchij Kamen. Walnij reef. Blischnij reef. r899. 
111. Korabelnoje rookery 1895 .

112-114. North rookery. Behring Isld. I895.

115-120. Sekatschinskaja rookery. Copper Isld.

121. Rookery in Nerpitchja Bay.

122-125. Korabelnoje rookery. I895. Copper Isld.

126. The fight of bulls.

127. The bull who take away the females from other bulls.

125-131. Palata and Zapadnaja rookeries.

132. 133. Sekatshinskaja rookery in 1895 .

134. Rookery behind Stolbi (Korabelnaja) Copper Isld.

135. 136. Rookery in the Great Bay-Korabelnaja.

137. The end of Korabelnaja rookery.

138. Palata and Zapadnaja rookeries from the mountain.

139. Korabelnorskij column and rookery.

140. also " Copper Isld.

141. also Point and Bay.

142. Near Palata rookery.

143. The beach from Glinka to Pestchanaja Bay. Copper Isld.

144. Zapadnoje rookery till Korabelny Point.

145. In the Sand Bay near Preobragenskaja village.

146. Poloudennaja mountain. Poloudenny Point. Waterfall.

147. Poloudenny Bay and Kazarma Point. Behring Isld.

148. Poloudenny Bay.

149. Steller's arch.

150. Basaltic rocks near Nikolskoje village.

151. Eagle rock (basaltic rock).

159. From Nepropousk Point to Tonkoj Point. Behring Isld.

153-15.5. Sand hills, Behring Isld.

156. Sand hills. Table mountains. Behring lsld. The japanese sealing schooner drifted on shore.

157. Sea otter rocks. Copper Isld.

158. 159. Thunder storm on Behring. Isld.

160. The storm clouds, in summer. Behring Isld.

161-166. Nikolskoje village.

167. 168. Preobrazhenskoje village. Copper Isld.

169. 170. Burial-ground. Behring Isld.

171. The sea shore near Preobrazhenskoye.

172. Behring's monument Nikolski village.

173. Yurt, or sod hut. Nikolski. Behring Isld.

174. Korabelny village. Copper Isld.

175. Glinka village. Copper Island.

176. The greek orthodox church Nikolski village.

177-180. Iconostasis of the church.

181. The greek orthodox church, Preobrazhenskoye village. 
152. Iconostasis.

153. 154. Sea otter guard. Copper Isld.

185. 186. Ladiginski village.

187. Preobrazhenskaja Sopka 1925 feet.

188. The sea shore near Preobrazhenskoye village.

189-191. Meteorological station. Behring Isld.

192-199. Clouds. Behring Island.

200. Apothecary. Copper Island.

201. North rookery. I897.

202. 203. Governor's office. Nikolski. Behring Isld.

204. 205. The typical aleut (born in Attu).

206. 207. also (Athka Isld.).

208. 209. also (Kadiak type).

210. 211. also (Atkha).

212. 213. The aleut women.

214. Two sisters (aleuts).

215. Aleut Pankoff.

216. Aleut Pachomoff.

217. Mongrel from Copper Isld. (aleut-kirgise woman).

218. Aleut woman from Kuril Isld.--Simousir.

219-224. Groups of children. Behring Isld.

225-225. also Copper Isld.

229. 230. An aleutian family. Behring Isld.

281. Family from Kadiak.

232. also Aleuts-Iakutsk.

233. Kreol family. Behring Isld.

234. 235. The white men on the Commander Islands.

236. 237. Kamtschatkaen, wom an.

235. The japs from confiscated shoomer.

239. 240. Aleut watchman.

241. The kreols (from Sitka).

242. Aleut man \& wife.

243. Aleut (man) and wife (kreolka).

24t. Kreol aleut \& gipsymongrel.

245-260. Kreols. Behring Isld.

261-267. also Copper Isld.

268. Kreol (fort Ross-California).

269. Old kreol woman from Attu.

970. Kreol from Atkha.

271. „ from Kuril Islds.

272. An aleutian wedding.

273. The newly married couple.

27t. The aleutian family.

275. The kreol's family. 




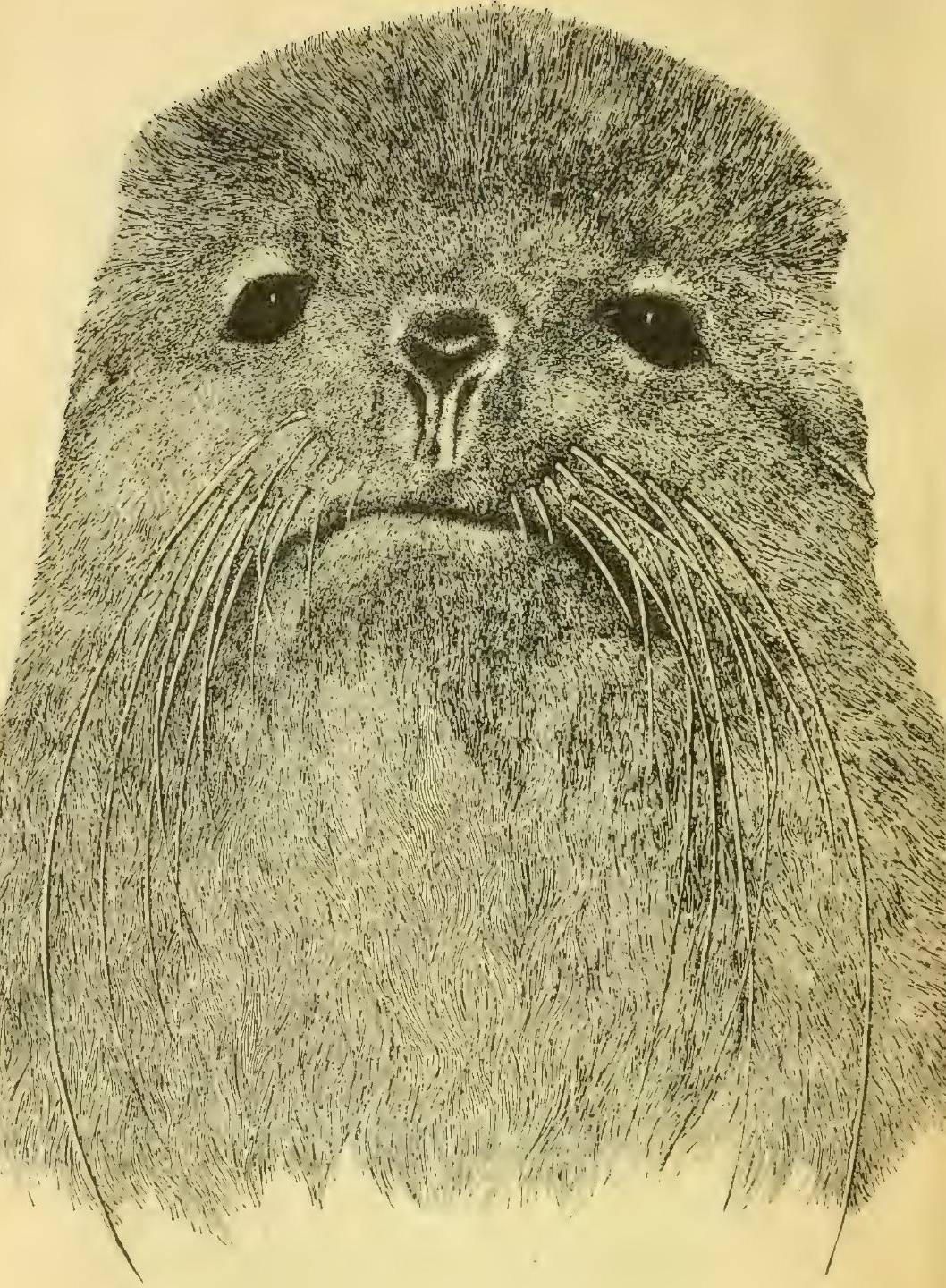

\section{Price 15 cop.}




39088008201592

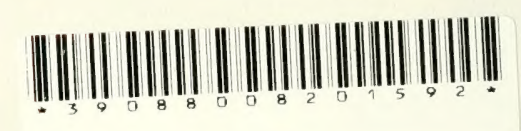

